\title{
RAPPORT OVER DE LOEBOE-BEVOLKING IN DE ONDERAFDEELING GROOT-MANDHELING EN BATANG NATAL.
}

\author{
DOOR
}

\author{
P. A. L. E. VAN DIJK.
}

Gewezen kontròleur van Groot-Mandheling en Batang Natal, thans kontrỏleur van Silindoeng.

Gedurende mijn verblijf in Groot-Mandheling en Batang Natal bezocht ik herhaaldelijk de op het gebergte in deze onderafdeeling verspreid wonende Loeboebevolking, in de eerste plaats in het belang der goevernements-koffiecultuur, daar dit gedeelte der bevolking eveneens cultuurdienstplichtig is en ten andere om door het verzamelen van gegevens over leefwijze, zeden en gewoonten der Loeboes daarover een zoo goed mogelijk rapport te kunnen uitbrengen, in voldoening van eene opdracht van den Gouverneur dezer kust.

Het bezoeken der Loeboes biedt op zich zelven niets bijzonders of merkwaardigs aan, daar zij op het gebergte verspreid in hunne ladangs wonen, evenals zulks het geval is ook met dat gedeelte der bevolking niet tot de Loeboes behoorende, dat door gebrek aan geschikte sawahgronden tot dezelfde leefwijze gedwongen is.

Alleen merkt men dadelijk op dat met eukele uitzonderingen de Loeboes, behalve hunne in de ladangs verspreid staande woningen, geen verzameling nog van andere woningen hebben in eene kampong, hetgeen bij Mandhelingsche en Ankolasche ladangbewerkers wel het geval is: deze hebben behalve hunne ladanghuisjes toch altijd eene vaste kampong waar de eigenlijke woningen bij elkander staan en die dan natuurlijk slechts een gedeelte van het jaar worden bewoond; verder ziet men dadelijk dat de ladangs der Loeboes over het algemeen niet zoo goed worden bewerkt, terwijl hunne woningen opvallend slecht zijn.

Zooals ik boven reeds opmerkte, zịjn zịj cultuurdienstplichtig en hebben zij hun aandeel aan het onderhoud van wegen en ke Volgr. VIII. 
bruggen, zoodat zịj ten deze ook niet van de overige bevolking verschillen.

Zij bewonen thans de oostelijke keten van het Barissangebergte, dat de grensscheiding vormt tusschen Padang Lawas en Groot-Mandheling en wel meest de hellingen naar de zijde van Mandheling.

De plaatsen waar zij zich ophouden en hunne ladangs gelegen zijn, noemt men meest Pagarans. Deze staan onder het bestuur van eigen ripéhoofden, welke dan weder onder toezicht staan van de kamponghoofden der Mandhelingsche kampongs, waaronder de Loeboes ressorteeren; ook staan bedoelde ripéhoofden wel direkt onder het koeria- of onderkoeriahoofd.

Zij zijn als volgt onder de verschillende koeria's en Mandhelingsche kampongs verdeeld:

I. Koeria Kotta Siantar.

Kampong Kotta Siantar:

Pagaran Si Obon met 28 huisgezinnen

$\begin{array}{lllll}\text { " Aik Mata " } & 36 & \\ \text { " Si Gata " } & 15 & \end{array}$

Kampong Pidoli Lombang:

Pagaran Aik Banir met 40 huisgezinnen

"Si Papaga " 20 "

II. Onderkoeria Goenoeng Bringin:

Pagaran Babi

$\begin{array}{llll}\text { " Krambil } & \text { " } & 20 & \text { " } \\ \text { " Gala 2 } & \text { " } & 20 & \text { " } \\ \text { " Tobing na Indjang " } & 20 & \end{array}$

III. Koeria Goenoengtoea :

a. Kampong Goenoengtoea :

Pagaran Baroehoer met 18 huisgezinnen

Arsé djoeloe " 7 "

Si Ala Paijong " 10 "

b. Kampong Ipar Bondar:

Pagaran Sopo Batoe met 14 huisgezinnen

c. Kampong Malintang-djoeloe:

Pagaran Si Boeang Anak met 6 huisgezinnen

" Aik Matandang " 4 "

Dus te zamen 291 huisgezinnen.

Rekent men per huisgezin \pm 5 zielen, wat gerust aangenomen kan worden aangezien in sommige huisgezinnen tot 6 en 7 kinderen voorkomen, dan verkrijgt men een globaal cijfer van \pm 1455 zielen. 
ALGEMEENE BEMERKINGEN OMTRENT AFKOMST, GESCHIEDENIS, LEEFWIJZE, ZEDEN EN GEWOONTEN, ENZ.

De Loeboes van Groot-Mandheling, evenals de Oeloes van Klein-Mandheling, behooren tot een en denzelfden stam en zijn Maleiers, hetgeen al dadelijk blijkt uit hunne taal die eigenlijk een verbasterd maleisch is; die taal wordt echter niet meer door alle Loeboes gesproken; zoo bijjv. spreken die van de onderkoeria Goenoeng Bringin uitsluitend Mandhelingsch, zulks tengevolge van den voortdurenden omgang met de Mandhelingsche bevolking en ook al uit vrees voor bespotting. De overige Loeboes spreken onder elkander echter meestal hunne eigene taal, maar een groot gedeelte, ja de meesten, vooral de iet wat meer beschaafden en de hoofden spreken ook het Mandhelingsch; een eigen letterschrift of litteratuur bezitten zij niet, een bewijs te meer dat zij geen zelfstandig volk zijn, maar tot den maleischen stam behooren.

Hunne taal, die oorspronkelijk wel goed maleisch zal geweest zijn, is door hun langdurigen omgang met de Mandhelingers reeds zeer verbasterd, zoodat men er bijna evenveel Mandhelingsche als maleische woorden in vindt.

De taal der Oeloes helt meer naar het Rausche dialekt.

Volgens Dr. J. J. de Hollander en anderen zouden zij afkomstig zijn evenals hunne stamverwanten de Oeloes, van de Padangsche Bovenlauden, en wel uit het vroeger rijk van $\mathrm{Pa}$ garoeijaeng, waaruit zij door burgeroorlogen zouden verdreven zijn, daarna Noordwaarts zijn getrọken, zich gevestigd hebben aan de Loeboerivier, eene zijtak van de Rokankanan en van daar door de Padang-Lawassers over het grensgebergte, de Barissan, naar Mandheling verdreven zijn. Van bedoelde rivier zouden zij dan ook hun naam ontleend hebben.

Volgens anderen, als bijv. Willem Iskander, zouden zij oorspronkelijk op Malakka hebben te huis behoord en wel in dat gedeelte dat den naam draagt van Roembo of Ramba (Rembau?) de daar wonende zwervende bevolking toch is hier in Mandheling bekend onder den naam van Loeboe djalang (wilde Loeboe). Van daar staken zij de straat van Malakka over, kwamen op de kust van Sumatra en vestigden zich aan de Koeboerivier, die zich in genoemde straat uitstort.

Daar de gronden langs deze rivier hun niet geschikt en vruchtbaar genoeg roorkwamen, trokken zij verder landwaarts in en 
kwamen zoodoende als boven reeds werd vermeld in PadangLawas bij de Loeboerivier terecht en, toen zij van daar verdreven werden, in Groot Mandheling.

Welke van deze beide veronderstellingen de juiste is, kan ik moeielijk beslissen; de Loeboes welke ik naar hunne af-en herkomst vroeg, wisten mij alleen mede te deelen dat zij, vóór dat zij in Mandheling kwamen, hadden gewoond aan de Loeboerivier, de zijtak van de Rokan-Kanan.

Het zoude echter zeer goed mogelijk kunnen zijn dat zij niet hunnen naam aan genoemde rivier hebben ontleend, maar dat integendeel de rivier van hen haar naam heeft gekregen, en in dien geest opgevat zou de laatste onderstelling misschien de juiste zijn; want hunne verhuizing naar Mandheling noet reeds ongeveer in de helft der zestiende eeuw hebben plaats gehad.

Over het barissangebergte getrokken zijnde, zetten de Loeboes zich neêr aan den oorsprong van het riviertje Aik Mata en leefden daar eenigen tijd ongestoord.

Op zekeren dag kwamen echter langs de kampong KottaSiantar in de Aik Mata pisangstammen en djagongsteelen afdrijven, hetgeen den toenmaligen radja van Kotta-Siantar Jang dipertoean I op het denkbeeld bracht dat er bovenstrooms in het gebergte vreemdelingen moesten wonen; hij zond onmiddellijk zijne hoeloebalangs met eene bende volk langs de Aik Mata het gebergte in en weldra vonden deze dan ook de daar zich neergezet hebbende I ooboebevolking. De Loeboes werden onderworpen, tot slaven verklaard en schatplichtig gemaakt aan de vorsten van Kotta-Siantar. Onder deze voorwaarden en verder. lat zij stipt de bevelen der Kotta-Siantarsche hoofden zouden opvolgen, verzochten en verkregen zij vergunning dat zij hunne woonplaatsen op het gebergte mochten blijven behouden, daar zij het kampongleven geheel reeds ontwend waren en zich liever in de bosschen ophielden.

De twee oudsten of hoofden dier Loeboes waren toen Singa Tandang en Singa Babi; tengevolge van eene vredebreuk tusschen deze beiden verhuisde Singa Babi met zijn volk naar Si Mandir nabij het tegenwoordige Goenoeng Bringin gelegen en nam daar eveneens den naam aan van Radja Singa Tandang; een gedeclte der overige Loeboes rakte toen ook over verschillende gedeelten van het gebergte waar zij thans nog verspreid wonen.

De Radja Singa Tandang van Si Mandir kreeg geschil met 
zijn meester den Jang dipertoean van Kotta-Siantar over het niet betalen van sene vrij zware boete hem opgelegd, wegens het niet opvolgen der hadatvoorschriften bij het dooden van wild.

De boete niet kunnende betalen en bevreesd voor den Jang dipertoean, verhuisde hij met het grootste gedeelte zijner onderhoorigen naar Klein-Mandheling en vestigde zich te Penjangit, war hij in voortalurenden onmin en oorlog met de Rauenaars leefde, tengevolge van diefstallen en roofpartijen door zijne onderhoorigen gepleegd.

Later onderstemnde hij den radja van Pakanten, die gehuwd was met eene dochter van Radja Goenoeng, zoon van den Jang dipertoean, tegen de Ranenaars en toen het hun gezamenlijk gelukto deze te verdrijven, verklarde Radja Goenoeng als belooning Singa Tandang en zujn volk te Penjangit ontheven van de slarernij en vrij.

Gedurende het leren van den Jang dipertoean I brak een oorlog uit tusschen den vorst van Penjaboengan, Baginda Mangaradja Enda en den vorst van Padang Garoegoer met dions bondgenooten de radja's van Pidoli Lombang en Pidoli Boekit, Baginda Mangaradja Lnda riep zijn zoon den Jang dipertoean $\mathrm{I}$ te hulp, en het gelukte dezen laatste de beide genoemde radja's van Pidoli Lombang en Pidoli Boekit te verdrijven en de kampong Padang Garoegoer door verraad in te nemen. Van deze behaaldè overwinningen en voordeelen maakte de Jang dipertoean gebruik om in die verschillende kampongs zijne zonen als hoofden aan te stellen en verhief hij achtereenvolgens Baginda Solohan, Batara Goeroe en Mangaradja Mandheling tot hoofden van Pidoli Lombang, Goenoeng Toea en Pidoli Boekit. Beide eerstgenoemde radja's waren van dezelfde moeder en kregen, daar deze zich steeds vriendelijk tegenover de Loeboe-slaven gedroeg, van hun vader ieder eenige Loeboes ten geschenke, die zij naar hunne respectieve kampongs overbrachten. De tweede vrouw van den Jang dipertoean, moeder van Mangaradja Mandheling, het aangewezen hoofd van Pidoli Boekit, behandelde hare slaven slecht, weshalve haar zoon ook geen Loeboes ten geschenke kreeg. Het is daarom dat thans alleen de Troeboebevolking in deze onderafdeeling voorkomt bij de Koeria Kotta Siantar, de onderkoeria Goenaeng Bringin, de kampong Pidoli Lombang en de koeria Goenaeng Toea.

Uiterlijk. De Loeboes hebben de maleische type en zijn over het algemeen gespierder, grover en flinker gebouwd dan 
de Mandhelingers; vooral is dit zichtbaar bij die welke door onreinheid niet aan huidziekten lijden, of door het eten van allerlei slecht voedsel een ziekelijk voorkomen hebben.

Over het algemeen zijn zij lui en alleen de honger dwingt hen hunne ladangs te bewerken en koffie aan te planten; zij zijn vrij koppig en diefachtig, doch overigens tegenover het Europeesch bestuur en de over hen gestelde Mandhelingsche hoofden vreesachtig en gedwee.

In humne ladangs teelen zij rijst, oebie, djagang, keladi, slechte tabak en koffie.

Verder houden zij zich bezig met het verzamelen van boschproducten, als rottan, damar, idjoek enz.

K leeding. De kleeding der mannen, wanneer zij in hunne ladangs aan den arbeid zijn, bestaat dikwijls slechts uit een tjawat; wanneer zij echter de passars bezoeken of op weg zijn en humne hoofden bezoeken, onderscheidt zich hunne kleeding weinig van die der overige bergbevolking, alleen is die wat morsiger en armoediger; meer en meer volgen zij in kleeding echter de overige Mandhelingsche bevolking. Kleederen, uit boomschors vervaardigd, ziet men zelden of in het geheel niet meer.

De vrouwen dragen gewoonlijk een lap om den middel vastgemaakt en reikende tot aan de knieën. De meer beschaafde, zoo ook de vrouwen en dochters der hoofden, zijn op dezelfde wijze als de Mandhelingsche vrouwen gekleed.

W a pens. Hunne wapens bestaan voornamelijk uit blaaspijpen, waarmede zij tot op vrij grooten afstand met ipoe vergiftigde pijltjes kunnen blazen, messen, bijlen, welke laatste ook bij den aanleg van ladangs worden gebezigd, enz.

Het ipoevergift is vrij krachtig en doodt snel.

Voedingsmiddelen. Behalve de in de ladangs geteelde producten en hetgeen de bosschen aan vruchten, wortels en planten opleveren, voedt zich de Loeboe bijna met het vleesch van alle mogelijke dieren, zooals dat van tijgers, eekhorens, vledermuizen, ja vroeger zelfs en misschien thans ook nog wel nu en dan met dat van alle slangensoorten.

Voorts zijn er velen die alle denkbare insecten als kevers, wormen, torren enz. nuttigen, terwijl zij over het algemeen niet afkeerig zijn van bedorven vleesch, als dat van karbouwen, koeien en varkenskrengen, ja, dit integendeel smakelijker nog vinden dan versch vleesch.

Het hoofd van Goenoeng-Bringin vertelde mij onder anderen,
Downloaded from Brill.come4/26/2023 12:02:48PM via free access 
dat hem een oude Loeboe bekend was, die verklaarde alle mogelijke kruipende en het vleesch van alle viervoetige dieren te nuttigen, met uitzondering van dat van den duizendpoot en de schorpioen.

De gevolgen van het nuttigen van dergelijk onrein voedsel blijven dan ook bij velen niet uit. Zij zijn met huidziekten behebt en hebben steeds, ten minste een groot gedeelte, een zeer onaangename geur bij zich.

In vroegere jaren hielden de Loeboes over het algemeen zeer veel varkens en werden ook wilde zwijnen veel door hen gejaagd ter wille van hun vleesch; ook thans eten zij dit vleesch gaarne, zoowel versch als bedorven. Door den invloed der Mandhelingsche hoofden is echter het houden van varkens bijna geheel, zoo niet geheel opgehouden, daar ik die dieren althans bij hunne woningen niet meer heb aangetroffen.

Bij warm weder houden velen zich soms uit luiheid met niets anders bezig dan het steken van visschen aan de kanten der rivieren, die dan na even gepoft te zijn in het vuur, worden genuttigd. Zij blijven dikwijls geheele nachten buiten in de bosschen en schijnen weinig vrees voor tijgers en ander wild gedierte te koesteren; zoo zullen zij bijv. des avonds of ook wel midden in den nacht door de bosschen naar hunne verblijven terugkeeren, wanneer zij zich om de een of andere reden bij hun hoofden hebben moeten vervoegen en niettegenstaande hum een nachtverblijf wordt aangeboden.

De Loeboes baden zich zelden, ja bijna nooit, hetgeen opmerkelijk is, daar bijna overal in de nabijheid humner woningen goed en helder water te vinden is; de meesten baden zich eens in de 4,5 à 6 maanden; de reden dezer onreinheid ligt in hunne luiheid, ongewoonte, vrees voor koude en koorts; het is dan ook te begrijpen waarom velen van hen aan huidziekten lijden.

W on ingen. Hunne woningen zijn over het algemeen ellendige krotten op palen of op den grond; die van de hoofden zien er natuurlijk nog het best uit, maar velen hebben dikwijls niets anders dan een hutje op den ruwen grond geplaatst, tegen welks buitenwanden dikwijls de ilalang manshoogte opgroeit. Daarin woont dan dikwijls eene geheele familie.

Liefst wonen zij zoover mogelijk van elkander om niet steeds met elkander twist te hebben, voornamelijk over hunne kinderen.

Het huisraad is natuurlijk van de eenvoudigste soort en 
bestaat uit enkele potten of pannen door hen op de passars gekocht.

Geboorte. Bij de geboorte van een kind gebeurt niets bijzonders; over het algemeen draagt men er weinig zorg voor en worden zij ruw behandeld. Zij zien er echter meestal gezond uit; men heeft liever jongens dan meisjes.

Huwelijk. Wanneer een jongman huwen wil en zich een meisje heeft gekozen, zendt hij zijne moeder naar die van het meisje om deze over de zaak te polsen; blijkt daaruit dat de zaak haar beslag zal kunnen krijgen, dan begeeft zich des jongman's vader met zijne familieleden naar het huis van 's meisjes ouders, medebrengende een bamboe met soerie (ongegiste palmwijn). De vader van het meisje heeft intusschen ook de meeste zijner bloedverwanten verzameld en nu wordt gesproken over de huwelijksgift door den jongeling voor het meisje te betalen en deze vastgesteld.

De huwelijksgift (djoedjoeran) bij de Loeboes bestaat niet uit geld, maar in een werk (pakerdjaän) zooals het bij hen genoemd wordt.

Volgens de adat moet de jongeling alvorens zijn meisje te kunnen huwen, aản hare ouders afleveren een met rijist beplante ladang van 12 koelaks (60 kattis) rijst, een huis van 3 vadem lang en eene kleine soppo.

Aan deze vastgestelde huwelijksgift houdt men zich echter meestal niet.

Bijna altijd is zij minder en hangt zulks dan ook af van het resultaat der onderhandelingen tusschen beide partijen.

Verder bestaat nog thans bij de Loeboes het gebruik dat de jongman, om zijne vaardigheid in het klimmen te bewijzen, van een der hoogste boomen der door hem als djoedjoeran aan te leggen ladang, met zijn kapmes den kop of kroon moet afkappen (toengkap anabatan).

Kan hij dit niet, dan kan hij daarvan vrij komen door het verbeuren van een kip met rịjst.

Zelden wordt vóór de levering der boven vastgestelde djoedjoeran het huwelijk gesloten; gebeurt dit echter toch, dan geschiedt zulks natuurlijk met goedvinden van de ouders van het meisje.

Zoolang het huwelijk niet is gesloten, is de jongman verplicht telkens als hij in zijne eigene ladangs padi snijdt of anderen oogst inhaalt, daarvan aan de ouders van het meisje 
te brengen 6 koelaks padi, 6 koelaks djagong, pisang met gekookte rijst en een kip; eveneens moet hij, als hij een varken, hert of ander dier op de jacht doodt, daarvan een gedeelte aan zijn schoonvader in spé komen brengen.

Vergeet de bruidegom vóór het huwelijk een dezer laatste voorschriften na te komen, dan heeft de vader van het meisje het recht de overeenkomst voor ontbonden en verbroken te verklaren en vallen de als djoedjoeran reeds gereed gemaakte ladang en het huis ook hem als eigendom toe.

Ontstaat er twist in een huisgezin tusschen man en vrouw en verstoot hij haar zonder bepaalde wettige redenen, dan vervalt de vroeger door hem betaalde djoedjoeran geheel aan de familie der vrouw.

Heeft deze laatste echter schuld en is zij oorzaak van den twist; vraagt zij echtscheiding en volgt die, dan kan de man zijne vroeger betaalde djoedjoeran geheel terugeischen. Zoodra de djoedjoeran is geleverd en aan alle gestelde voorwaarden voldaan, haalt de bruidegom zijne bruid af, vergezeld van zijne bloedverwarten en medebrengende alweder een bamboe met palmwijn (soeri of nira) en met bloemen omkranst.

Is men teruggekomen in het huis van den bruidegom, of althans het huis dat door het echtpaar zal worden bewoond, dan wordt daar gegeten en gedronken; de vader van de bruid geeft deze aan den bruidegom over tegelijk met al de op hem rustende verantwoordelijkheid; de Loeboes zeggen met alles goeds en kwaads en daarmede is de plechtigheid afgeloopen en het huwelijk gesloten.

Teder kan zooveel vrouwen nemen als hij wil.

Overlijden. Vroeger werden de lijken bij de Loeboes, zoowel van mannen als vrouwen begraven in stukken uitgeholde boomstammen, die, na weder gesloten te zijn, in den grond werden begraven; was 't het lijk van een hoofd, dan werd de boomstam gewoonlijk nog versierd met allerlei figuren. Verder gaf men de overledenen in hunne laatste rustplaats van alles mede als wapens, gereedschappen, kleederen, rijsst, enz., opdat zij hiernamaals dadelijk de noodigste zaken bij de hand zouden hebben. In den mond werd een sirihpruim gestoken. Ook thans worden de lijken op dezelfde wijze behandeld; alleen sluit men ze niet eerst in uitgeholde boomstammen, maar worden zij eenvoudig in een kuil begraven.

De Loeboes gelooven aan de onsterfelijkheid der ziel en een 
leven hiernamaals ook op deze aarde, maar de zielen der afgestorvenen, hoewel zij geheel op dezelfde wijze leven en zich bezig houden als de levenden, zijn voor deze laatsten onzichtbaar.

Omgekeerd kunnen de afgestorvenen de levenden wel zien en hen nagaan en dikwijls vervolgen. Bij ziekten varen de zielen der afgestorvenen in de lichamen der zieken. De zieke noemt dan den naam op van een overleden bloedverwant en de omstanders begeven zich oogenblikkelijk naar diens graf, met spijs en drank, ten einde diens ziel goedgezind voor den zieke te stemmen.

Sterft eene vrouw echter in het kraambed, dan gaat hare ziel over in het lichaam van een of ander dier, bijv. een moesang, beer of vogel. Deze dieren zijn meestal den menschen dan slecht gezind en hebben het vermogen des nachts de menschelijke stem na te bootsen.

Godsdienstige begrippen. De Loeboes onderscheiden goede en kwade geesten. In de eerste plaats aanbidden zij de ziel van Singa Tandang, hun vroeger hoofd en voorvader. Deze geest omzweeft hen en is hun beschermer tegen de booze geesten. Bij het aanroepen van den geest van Singa Tandang gebruiken zij de volgende woorden: "Na marjamba na manjaroe do hokoe di soemangea ni Singa Tandang nan dohoe!" (Ik aanbid en prijs den geest van den eersten Singa Tandang).

Verder zijn als goede geesten bekend twee afstammelingen van Singa Tandang, nl. Oeloebalang Si Sahan Sampoeran, en Aman Djaroendjoeng di Langit Lamadom. De algemeene benaming voor deze geesten is tinagassan (plaats waar men v raagt).

Volgens de vroegere adat werden en worden bij het aanroepen van Djaroendjoeng di Langit een witte kip en bij Sahan Sampoeran eene roode kip als offer aangeboden; zulks heet "apoessan manoek."

Bedoelde kippen worden niet geslacht, maar zijn eenmaal aangeboden als het ware heilig geworden; zij worden verzorgd en bewaard en als zij te oud beginnen te worden, verwisseld met een jongere als plaatsvervangster.

Het santal booze en den mensch vijandig gezinde geesten is onbepaald; zij heeten hantoe of begoe en zijn overal te vinden in rivieren, rotsholen bij groote boomen, op zekere gronden, enz. 
Herhaaldelijk gaan Loeboes tot den islam over; zulks is echter meestal slechts in naam on zich geene bespotting of minachting van het overige gedeelte der bevolking op den hals te halen. Enkele houden aan hun nieuwen godsdienst en hunne voorschriften vast; de meesten vergeten die echter even spoedig en schenden de voorschriften, zoodra zij een varken of hond of onrein voedsel machtig kunnen worden.

Penjaboengan, 2 Maart 1883. 